\title{
NLPR3 inflammasome inhibition alleviates hypoxic endothelial cell death in vitro and protects blood-brain barrier integrity in murine stroke
}

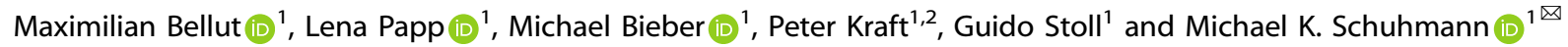 \\ (c) The Author(s) 2021
}

In ischemic stroke (IS) impairment of the blood-brain barrier (BBB) has an important role in the secondary deterioration of neurological function. BBB disruption is associated with ischemia-induced inflammation, brain edema formation, and hemorrhagic infarct transformation, but the underlying mechanisms are incompletely understood. Dysfunction of endothelial cells (EC) may play a central role in this process. Although neuronal NLR-family pyrin domain-containing protein 3 (NLRP3) inflammasome upregulation is an established trigger of inflammation in IS, the contribution of its expression in EC is unclear. We here used brain EC, exposed them to oxygen and glucose deprivation (OGD) in vitro, and analyzed their survival depending on inflammasome inhibition with the NLRP3-specific drug MCC950. During OGD, EC death could significantly be reduced when targeting NLRP3, concomitant with diminished endothelial NLRP3 expression. Furthermore, MCC950 led to reduced levels of Caspase 1 (p20) and activated Gasdermin $\mathrm{D}$ as markers for pyroptosis. Moreover, inflammasome inhibition reduced the secretion of pro-inflammatory chemokines, cytokines, and matrix metalloproteinase-9 (MMP9) in EC. In a translational approach, IS was induced in C57BI/6 mice by 60 mins transient middle cerebral artery occlusion and 23 hours of reperfusion. Stroke volume, functional outcome, the BBB integrity, and-in good agreement with the in vitro results-MMP9 secretion as well as EC survival improved significantly in MCC950-treated mice. In conclusion, our results establish the NLRP3 inflammasome as a critical pathogenic effector of stroke-induced BBB disruption by activating inflammatory signaling cascades and pyroptosis in brain EC.

Cell Death and Disease (2022)13:20; https://doi.org/10.1038/s41419-021-04379-z

\section{INTRODUCTION}

Endothelial cells (EC) play a central role in maintaining blood-brain barrier (BBB) integrity. In ischemic stroke (IS), which is a leading cause of death and disability worldwide, the BBB is progressively impaired and its breakdown is associated with poor long-term outcomes and adverse treatment effects such as intracranial hemorrhages $[1,2]$. There is increasing evidence that inflammatory processes contribute to stroke development and bleeding complications [3-7], but the role of EC within these has been largely neglected.

Inflammasomes in general, and the NLR-family pyrin domaincontaining protein 3 (NLRP3) inflammasome in particular, are molecular protein complexes that sense cellular deviation from homeostasis as a danger signal and subsequently initiate inflammatory responses [8]. They are responsible for the activation of Caspase 1 and its downstream pro-inflammatory cytokines interleukin (IL) 1b, IL18, and the pyroptosis-inducing Gasdermin D (GSDMD). Recently, we have shown the potential of NLRP3 inhibition to reduce infarct development during IS [9]. NLRP3 was expressed in neurons and EC. NLRP3-induced inflammation plays a detrimental role in systemic endothelial dysfunction (e.g., large vessel disease, arteriosclerosis) [10], but the role of endothelial
NLRP3 induction in stroke and its impact on BBB integrity is largely unknown.

Here, we show that the inhibition of NLRP3 prevents hypoxic/ ischemic BBB disruption by reducing EC death mediated through the pyroptosis pathway.

\section{MATERIALS AND METHODS \\ Materials}

All used materials are separately listed in detail in the Supplement.

\begin{abstract}
Animals
Animal experiments were approved by local governmental authorities (Regierung von Unterfranken) and conducted in accordance with the US National Institutes of Health Guidelines for the Care and Use of Laboratory Animals. Moreover, the experiments were designed, performed, and reported according to the Animal Research: Reporting of In Vivo Experiments guidelines [11]. We used 6-8-week old male C57BI/6N mice, purchased from Charles River Laboratories (Sulzfeld, Germany). In all, 10 mice were used for infarct size measurement, clinical tests, and immunohistochemistry (five treated with vehicle, five with MCC950). 22 animals ( 11 treated with MCC950, 11 treated with vehicle) were used for matrix metalloproteinase-9 (MMP9) measurement. Out of these 22 animals,
\end{abstract}

\footnotetext{
${ }^{1}$ Department of Neurology, University Hospital Wuerzburg, Josef-Schneider-Str. 11, 97080 Würzburg, Germany. ${ }^{2}$ Department of Neurology, Klinikum Main-Spessart, Grafen-von-

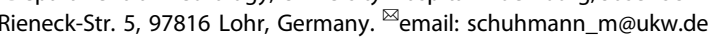

Edited by Professor Alexei Verkhratsky
} 


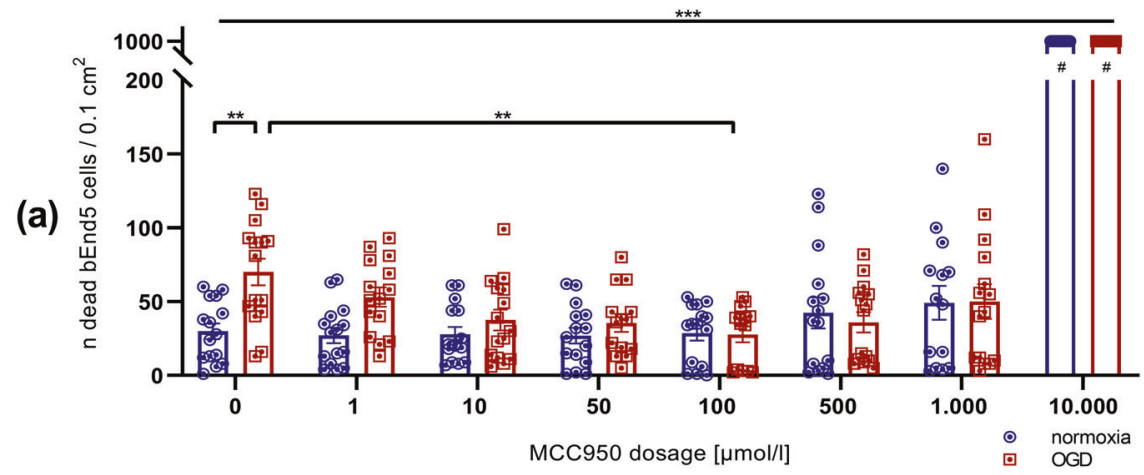

(b)
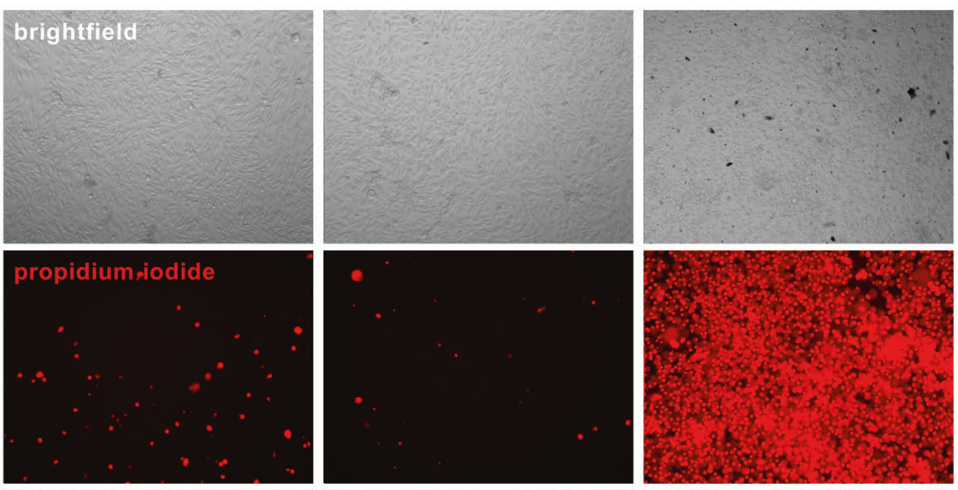

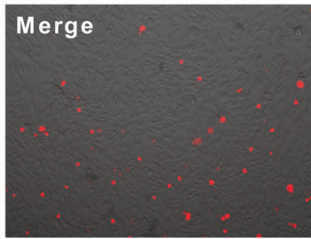

1

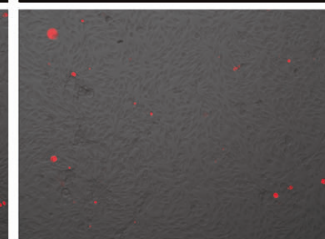

100

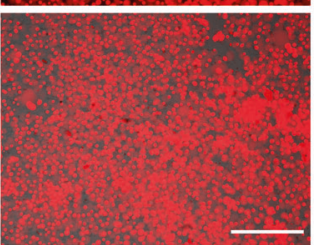

10.000

MCC950 dosage $[\mu \mathrm{mol} / \mathrm{l}]$

Fig. 1 The comparison of bEnd5 after $24 \mathrm{~h}$ of either normoxia or OGD shows a significantly higher rate of cell death under OGD conditions. The MCC950 dilution series within the bEnd5 cell culture favors the $100 \mu \mathrm{mol} / \mathrm{I}$ MCC 950 concentration with a significant reduction of cell death under OGD. a Number of apoptotic bEnd5 cells per $0.1 \mathrm{~cm}^{2}$ after $24 \mathrm{~h}$ of either normoxia (blue) or OGD (3.0\% $\mathrm{O}_{2}, 5.0 \%$ $\mathrm{CO}_{2}, 95 \%$ humidity, $37.0^{\circ} \mathrm{C}, 1 \mathrm{~g} / \mathrm{l}$ glucose, red) depending on the concentration of the initial MCC950 treatment in comparison to untreated control cells ( $n=15$ out of three independent experiments). \#: counting stopped at 1000 dead cells $/ 0.1 \mathrm{~cm}^{2}$. b Representative microscopic brightfield images of bEnd5 after $24 \mathrm{~h}$ OGD and immunofluorescent staining of the propidium iodide (red) uptake of these bEnd5 cells as cell death marker in selected MCC950 concentrations. In all, $\times 20$ objective; scale bar $=25 \mu \mathrm{m}$. Data were analyzed by one-way ANOVA with Tukey post hoc test. ${ }^{* *} p<0.01 ;{ }^{* * *} p<0.001$.

14 (seven treated with MCC950, seven treated with vehicle) were used for Western Blot analysis. After randomization,transient middle cerebral artery occlusion (tMCAO) was conducted for $60 \mathrm{~min}$. Surgery and evaluation of all readout parameters were performed blinded to the experimental groups. The group sizes were derived from previous $\mathrm{TMCAO}$-studies, which showed significant effects with a power of 0.8 and a probability of a type I error of $<0.5[9,12]$.

\section{Animal treatment}

Animals were treated with $100 \mu \mathrm{l}$ of the inflammasome-inhibitor MCC950 or the same volume of vehicle (1× PBS), which were administered by an intraperitoneal injection directly before occluding the MCA for $60 \mathrm{~min}$ [9].

\section{Ischemia model}

The tMCAO model was used to induce focal cerebral ischemia as described before [13]. The experiments were carried out blinded. An independent researcher not involved in data analysis coded and randomized the mice. To reduce the variability of our outcome parameters caused by sex differences only male mice were used [14]. Before tMCAO, the mice were anesthetized with $2.0 \%$ isoflurane in $\mathrm{O}_{2}(\mathrm{v} / \mathrm{v}) .200 \mathrm{mg} / \mathrm{kg}$ body weight metamizol was injected subcutaneously and $4 \%$ lidocaine gel was applied on the wound margins as analgesia. With a servo-controlled heating blanket, a body core temperature close to $37.0^{\circ} \mathrm{C}$ was maintained throughout surgery. After a midline neck incision, standardized silicon rubber-coated 6.0 nylon monofilament (\#6023910PK10; Doccol, Sharon, MA, USA) was inserted into the right common carotid artery and advanced via the internal carotid artery to occlude the origin of the MCA. After $60 \mathrm{~min}$, mice were re-anesthetized and the filament removed to allow reperfusion. To reduce infarct variability all mice were operated by the same operator. Operation time did not exceed $10 \mathrm{~min}$. The reperfusion time accounted for $23 \mathrm{~h}$.

\section{Triphenyltetrazolium chloride (TTC) staining}

Edema-corrected stroke volumes were assessed $24 \mathrm{~h}$ after $\mathrm{tMCAO}$, based on 2,3,5-triphenyltetrazolium chloride (TTC) staining (\#T8877, Merck). Animals were killed $24 \mathrm{~h}$ after $\mathrm{tMCAO}$ and brains were cut into three 2$\mathrm{mm}$-thick coronal sections. Slices were stained for $20 \mathrm{~min}$ at $37.0^{\circ} \mathrm{C}$ with 2.0\% TTC to visualize the infarctions. Edema-corrected infarct volumes were calculated by planimetry (ImageJ software, National Institutes of Health, Bethesda, MD, USA) [15].

\section{Assessment of functional outcome}

The global neurological deficits were quantified by conducting the Neuroscore, composed of the sum of the inverted Bederson score and the grip test, $24 \mathrm{~h}$ after stroke induction $[16,17]$. 


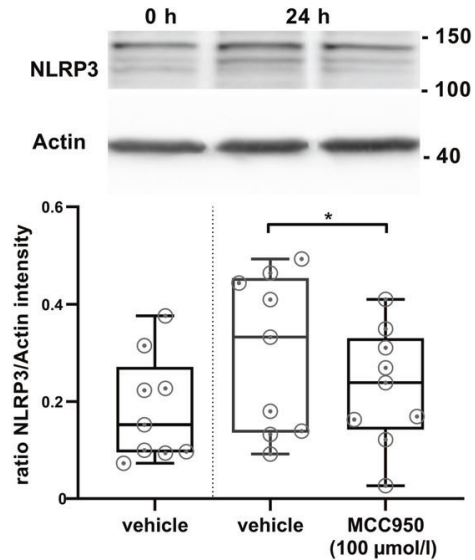

(a)

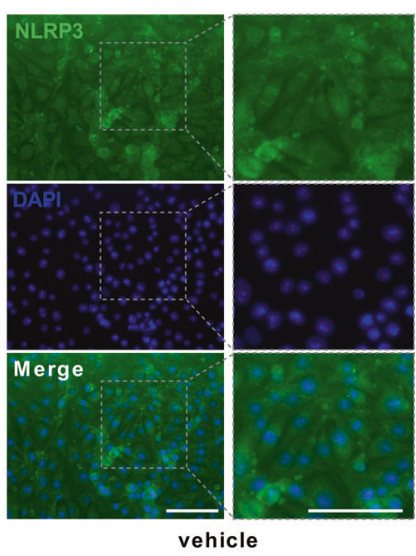

(b)

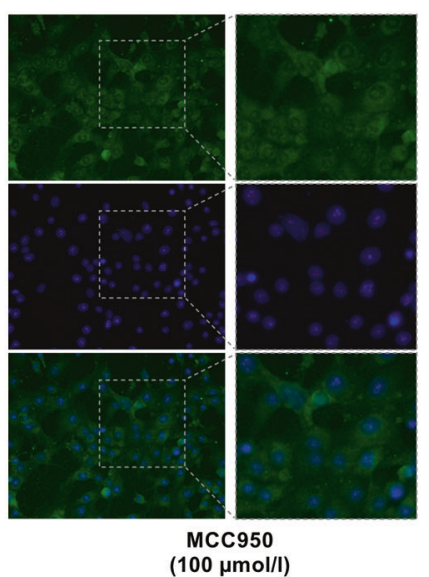

Fig. 2 bEnd5 express NLRP3 protein. The amount of NLRP3 protein is dependent upon OGD as well as MCC950 (100 $\mu \mathrm{mol} / \mathrm{I})$ treatment. a Top: representative Western Blot depicting the amount of expressed NLRP3 $(120 \mathrm{kDa})$ in bEnd5 lysates. To control protein loading $\beta$-actin was used (expected mass $\sim 42 \mathrm{kDa}$ ). Bottom: ratio of NLRP3 protein band intensity to actin as loading control after $0 \mathrm{~h}$ and $24 \mathrm{~h}$ of OGD ( $3.0 \% \mathrm{O}_{2}$, $5.0 \% \mathrm{CO}_{2}, 95 \%$ humidity, $37.0^{\circ} \mathrm{C}, 1 \mathrm{~g} / \mathrm{l}$ glucose) with vehicle or MCC950 (100 $\left.\mu \mathrm{mol} / \mathrm{l}\right)$ treatment $(n=9$ out of three independent experiments). b Representative NLRP3 (green) and DAPI (blue) immunofluorescence stainings of bEnd5 after $24 \mathrm{~h}$ of OGD either with vehicle or with MCC950 $(100 \mu \mathrm{mol} / \mathrm{l})$ treatment. Adjacent $\times 2$ magnification. In all, $\times 20$ objective; scale bar $=25 \mu \mathrm{m}$. Data were analyzed by unpaired $t$ test. ${ }^{*} p$ $<0.05$.

\section{Exclusion criteria}

Mice were excluded from endpoint analyses due to: (1) death before the predefined experimental endpoint; (2) Bederson score $=0$ (24h after tMCAO); (3) weight loss $>20 \%$ ( $24 \mathrm{~h}$ after tMCAO).

\section{bEnd5 cell culture}

The commercially available cell line bEnd 5 has been purchased from Merck (b.End5, \#96091930). It has been established from primary brain EC of $\mathrm{BALB} / \mathrm{c}$ mice. Immortalization has been carried out by infection of primary cells with retrovirus coding for the Polyomavirus middle T-oncogene. bEnd5 were grown in Dulbecco's Modified Eagle Medium (DMEM) (high glucose, $4.5 \mathrm{~g} / \mathrm{L}$ ), supplemented with $10 \%$ fetal calf serum (FCS) and $1 \% \mathrm{~L}-$ glutamine $(200 \mathrm{mM})$, in a humidified $(95 \%) 37.0^{\circ} \mathrm{C}$ incubator with $5.0 \% \mathrm{CO}_{2}$ and $21 \% \mathrm{O}_{2}$. bEnd5 were plated in $75 \mathrm{~cm}^{2}$ culture flasks and subcultured using $0.25 \%(\mathrm{w} / \mathrm{v})$ trypsin in $0.02 \%(\mathrm{w} / \mathrm{v})$ EDTA at $80 \%$ confluence. Media was changed every $2 \mathrm{~d}$ and cells chosen for experimentation were passaged between 18 and 24 times. For Western Blot/zymography analysis bEnd5 were subcultured in 24-well plates, for microscopy in ibidi slides until confluency.

\section{Oxygen and glucose deprivation (OGD)}

Confluent monolayers of bEnd5 were exposed to hypoxic $\left(3.0 \% \mathrm{O}_{2}, 95 \%\right.$ humidity, $5.0 \% \mathrm{CO}_{2}, 37.0^{\circ} \mathrm{C}$ ) and aglycemic conditions by replacing the culture medium with low glucose-medium (hypoxic DMEM low glucose with $1 \%$ L-glutamin without F(S). OGD medium was pre-incubated for $24 \mathrm{~h}$ under hypoxic conditions before administration.

\section{bEnd5 treatment}

bEnd5 were treated with varying concentrations of the inflammasomeinhibitor MCC950. MCC950 was dissolved as described above. As vehicle treatment, the same amount of pure culture or OGD medium was added. The investigators were blinded to the group allocation.

\section{Western blot analysis}

bEnd5 were cultured in 24-well plates until confluency. After cell lysis, the denatured protein was electrophoresed and transferred to a nitrocellulose membrane. Membranes were blocked for $1 \mathrm{~h}$ and incubated with the primary antibody at $4.0^{\circ} \mathrm{C}$ overnight. Thereafter, the membranes were incubated with horseradish peroxidase-conjugated Immunoglobulin G antibody (\#111-035-045, 1:10,000, Dianova, Hamburg, Germany) at room temperature for $1 \mathrm{~h}$. Proteins were detected using ECLplus (\#NEL104001EA, PerkinElmer, Waltham, MA, USA) and the ChemiDocTM Touch Imaging System (Bio-Rad, Hercules, CA, USA). To control protein loading, membranes were incubated with a $\beta$-actin monoclonal antibody (expected mass $\sim 42 \mathrm{kDa}$ ). After intense washing, membranes were blocked for $1 \mathrm{~h}$ and incubated with the primary $\beta$-actin antibody (\#A5441, 1:250,000, Merck) at $4.0^{\circ} \mathrm{C}$ overnight. Thereafter, membranes were incubated with horseradish peroxidase-conjugated Immunoglbulin G antibody (\#715-035150, 1:10,000, Dianova) at room temperature for $1 \mathrm{~h}$. Actin was detected as described above. Bands were quantified by densitometric analysis using Image Lab Analysis Software Version 5.2.1. (Bio-Rad, Hercules, CA, USA).

\section{Zymography}

MMP9 in the in vivo and in vitro model was detected by zymography as reported before [18]. In brief, either ipsilesional cortical or basal ganglial protein probes of tMCAO-treated mice or bEnd 5 supernatants after $0 \mathrm{~h}, 5 \mathrm{~h}$, $10 \mathrm{~h}, 24 \mathrm{~h}$ of OGD or normoxia were collected and mixed with equal volumes of sample buffer (20\% Glycin, $4.0 \%$ SDS, $2 \mathrm{mM}$ EDTA, $0.01 \%$ Bromophenol Blue, $125 \mathrm{mM}$ Tris-HCl pH 6.8). Next, samples were loaded on a $10 \%$ sodium dodecyl sulfate-polyacrylamide gel electrophoresis ( $0.1 \%$ gelatin). Then, gels were treated twice with $2.7 \%$ Triton X-100 solution for $2 \times 30 \mathrm{~min}$, washed in water, and incubated in developing buffer $(50 \mathrm{mM}$ Tris, $200 \mathrm{mM} \mathrm{NaCl}, 5 \mathrm{mM} \mathrm{CaCl}, 0.02 \%$ Brij- $35,40 \mathrm{mM}$ Tris- $\mathrm{HCl} \mathrm{pH} \mathrm{7.5)} \mathrm{at} 37.0^{\circ} \mathrm{C}$ overnight. Gels were stained with $0.25 \%(\mathrm{w} / \mathrm{v})$ Coomassie brilliant blue in $25 \%$ isopropanol $/ 10 \%$ acetic acid for $30 \mathrm{~min}$ and bleached with 50\% methanol and $10 \%$ acetic acid for 30 min until bands with diminished staining appeared. Gel images were captured with the ChemiDocTM Touch Imaging System and subsequently analyzed with ImageJ Analysis Software 1.52a.

\section{Cytometric bead array}

Cytometric Bead Arrays for CXCL1, CCL2, CCL5, and CXCL10 were performed with bEnd5 supernatants using LEGENDplex ${ }^{\text {TM }}$ fluorescent bead immunoassays according to the manufacturer's instructions. The readout was performed with the BD FACSlyric ${ }^{\mathrm{TM}}$ (Becton Dickinson, Franklin Lakes, NJ, USA).

\section{Enzyme-linked immunosorbent assay}

To determine IL1b and IL18 levels, commercially available ELISA kits were used (Mouse IL-1 beta ELISA Kit, \#ab197742, Abcam, Cambridge, UK; IL-18 Mouse ELISA Kit, \#BMS618-3, Thermo Fisher Scientific, Waltham, MA, USA). Cell lysates were prepared as described above. All reagents were provided with the kits and the ELISAs were performed according to the manufacturer's manual.

\section{Immunohistochemistry}

For histology brain tissue was cut in 2-mm-thick coronal sections, embedded in Tissue-Tek OCT compound, and frozen. Brain sections were 

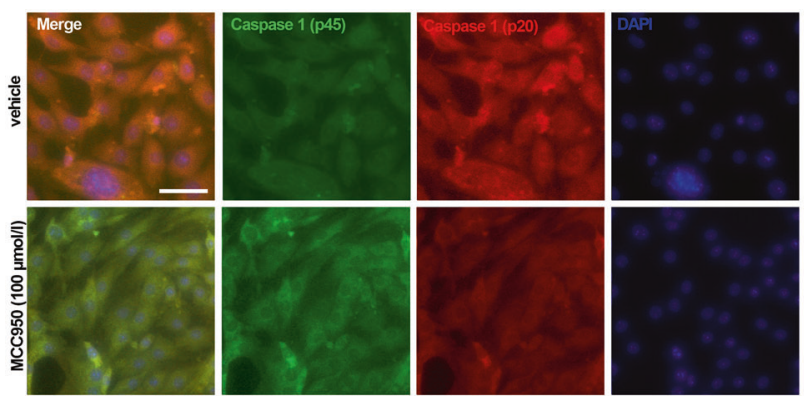

(a)
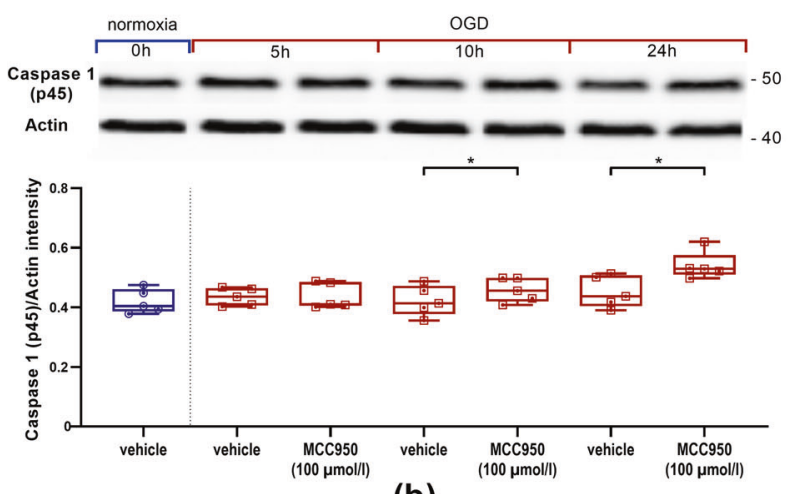

(b)

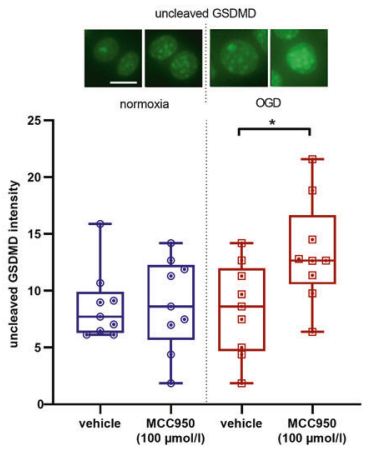

(c)

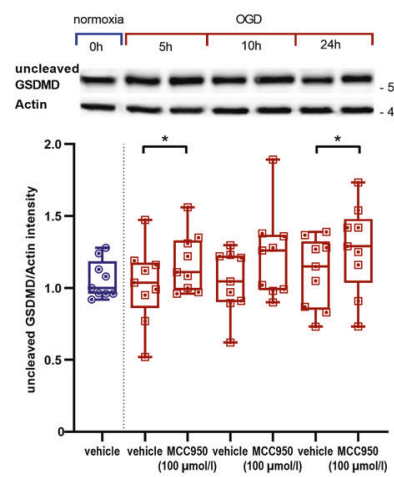

(e)

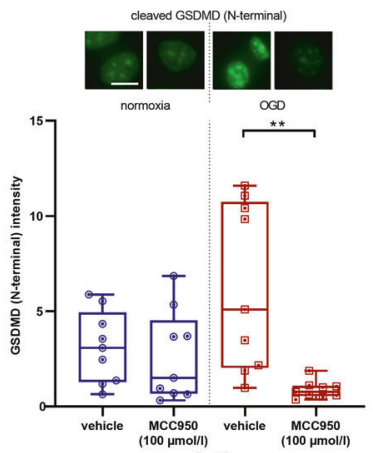

(d)

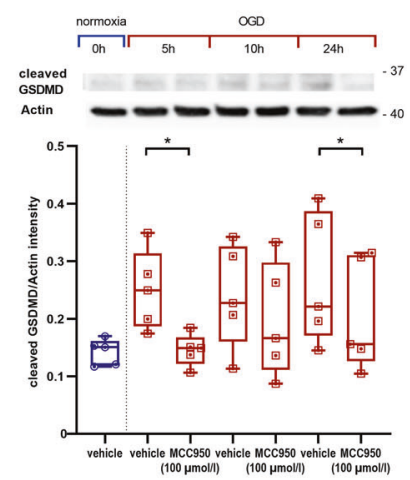

(f) cut on a cryostat into $10 \mu \mathrm{m}$ thin slices and used for all analysis. For immunohistochemistry, slices were post-fixated with ice-cold $100 \%$ methanol. Immunohistochemistry was performed according to standard procedures [12]. Mouse brains were stained for DAPI and TUNEL and with anti-NLRP3 (Anti-NLRP3/NALP3, mAb (Cryo-2), \#AG-20B-0014, 1:100, Adipogen Life Sciences, San Diego, CA, USA), anti-CD31 (Anti-CD31
Fig. 3 MCC950 (100 $\mu \mathrm{mol} / \mathrm{l})$ treatment reduces pyroptosis, indicated by lower levels of active Caspase 1 (p20), higher levels of pro-Caspase 1, elevated uncleaved GSDMD as well as reduced cytotoxic N-terminal GSDMD. a Representative pro-Caspase 1 (p45) (green), active Caspase 1 (p20) (red), and DAPI (blue) immunofluorescence stainings of bEnd5 after $24 \mathrm{~h}$ OGD $\left(3.0 \% \mathrm{O}_{2}, 5.0 \% \mathrm{CO}_{2}, 95 \%\right.$ humidity, $37.0^{\circ} \mathrm{C}, 1 \mathrm{~g} / \mathrm{l}$ glucose, red) either with vehicle or with MCC950 treatment. In all, $\times 20$ objective; scale bar $=25 \mu \mathrm{m}$. b Top: representative Western Blot depicting the amount of expressed proCaspase $1(45 \mathrm{kDa})$ in bEnd5 lysates. To control protein loading $\beta$-actin was used (expected mass $\sim 42 \mathrm{kDa}$ ). Bottom: ratio of proCaspase 1 (p45) protein band intensity to actin as loading control after $0 \mathrm{~h}, 5 \mathrm{~h}, 10 \mathrm{~h}$, and $24 \mathrm{~h}$ of OGD with vehicle or MCC950 $(100 \mu \mathrm{mol} / \mathrm{l})$ treatment $(n=5$ out of three independent experiments). c, d Top: representative immunofluorescence stainings of either uncleaved GSDMD or GSDMD (N-terminal) (green). Bottom: either uncleaved GSDMD or GSDMD (N-terminal) intensity of bEnd5 cell cultures after $24 \mathrm{~h}$ OGD with either vehicle or MCC950 (100 $\mu \mathrm{mol} / \mathrm{l})$ treatment ( $n=9$ out of four independent experiments). In all, $\times 40$ objective; scale bar $=5 \mu \mathrm{m}$. e, f Top: representative Western Blot depicting the amount of expressed uncleaved $(52 \mathrm{kDa})$ or cleaved (N-terminal) (32 kDa) GSDMD in bEnd5 lysates. To control protein loading $\beta$-actin was used (expected mass $\sim 42 \mathrm{kDa}$ ). Bottom: ratio of either uncleaved GSDMD or cleaved ( $\mathrm{N}$-terminal) GSDMD protein band intensity to actin as loading control after $0 \mathrm{~h}, 5 \mathrm{~h}, 10 \mathrm{~h}$, and $24 \mathrm{~h}$ of OGD with vehicle or MCC $950(100 \mu \mathrm{mol} / \mathrm{l})$ treatment $(n$ $=9$ or five out of three independent experiments). Data were analyzed by paired $t$ test. ${ }^{*} p<0.05 ;{ }^{* *} p<0.01$.

antibody, \#ab28364, 1:100, Abcam), anti-Albumin (Anti-Albumin antibody, \#ab106582, 1:100, Abcam). Cell cultures were dyed with TUNEL, DAPI, Propidium lodide (PI) and antibodies against NLRP3 (Anti-NLRP3/NALP3, mAb (Cryo-2), \#AG-20B-0014, 1:100, Adipogen Life Sciences), Caspase 1 (uncleaved) (Caspase 1 Monoclonal Antibody (5B10), \#14-9832-82, 1:100, Thermo Fisher Scientific), the p20 subunit of cleaved Caspase 1 (antiCaspase-1 (p20) (mouse), \#AG-20B-0042, 1:200, Adipogen Life Sciences) and Zonula Occludens 1 (ZO-1) (ZO-1 Polyclonal Antibody, \#61-7300, 1:1000, Thermo Fisher Scientific). Secondary antibodies were used in a dilution of 1:100. For measurement of albumin intensity, images at the level of the basal ganglia $(0.5 \mathrm{~mm}$ anterior from bregma) of five different animals per group were recorded with a microscope (Leica DMi8, DMC 2900/DFC 3000 G camera control, LAS X software, Leica, Wetzlar, Germany). Subsequently, after converting the images into 16-bit black/white files, the intensity of the albumin staining was compared between the ipsilesional and contralesional hemispheres with ImageJ Analysis Software 1.52a. bEnd5 cultivated on ibidi slides were visualized with transmitted light microscopy and apoptotic bEnd5 with fluorescence measurements after PI (1:200) staining with the above-mentioned microscope. The red fluorescent cells were counted. The fluorescence intensity of anti-GSDMD and anti-ZO-1 stainings were measured as described above.

\section{Statistical analysis}

Results are presented as box plots indicating the median, the 25th percentile, the 75th percentile, minimum and maximum. Error bars show the standard error of the mean. For statistical analysis, the GraphPad Prism 8 software was used. Data were tested for Gaussian distribution with the D'Agostino-Pearson omnibus normality test and then analyzed by one-way analysis of variance with post hoc Tukey adjustment for $p$ values. If comparing only two groups paired or unpaired-depending on the respective question-two-tailed $t$ tests were applied. Probability values $<0.05$ were considered to indicate statistically significant results.

\section{RESULTS}

NLRP3 inhibition leads to a higher endothelial survival after OGD

Our aim was to characterize the influence of the NLRP3-specific inflammasome-inhibitor MCC950 on EC. Therefore, we took advantage of the bEnd5 cell model that has frequently been shown to be suitable to study the responsiveness of brain EC 


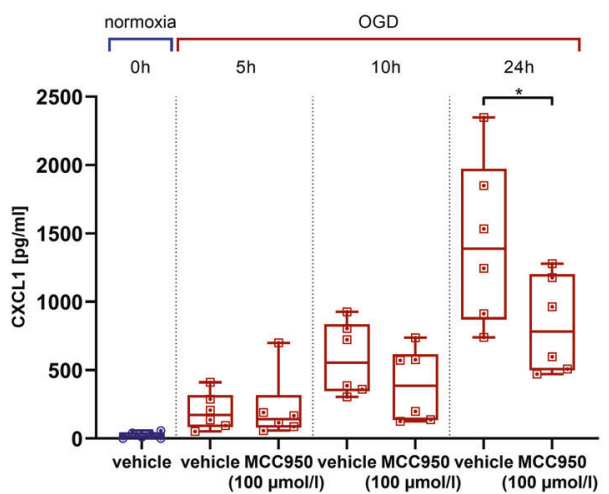

(a)

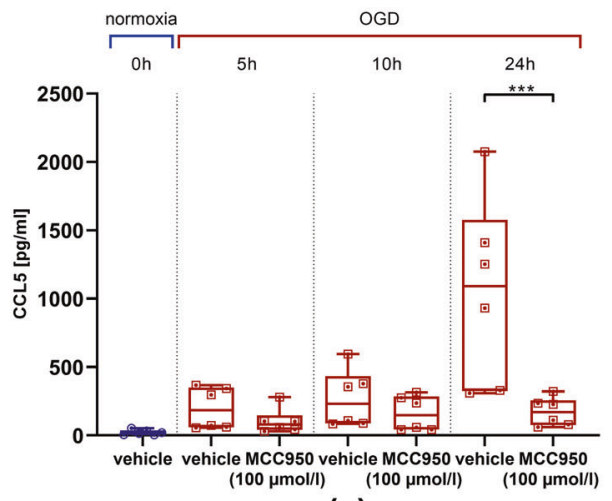

(c)

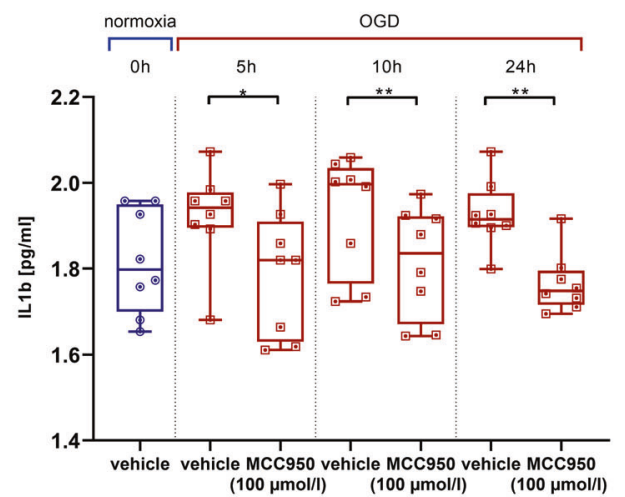

(e)

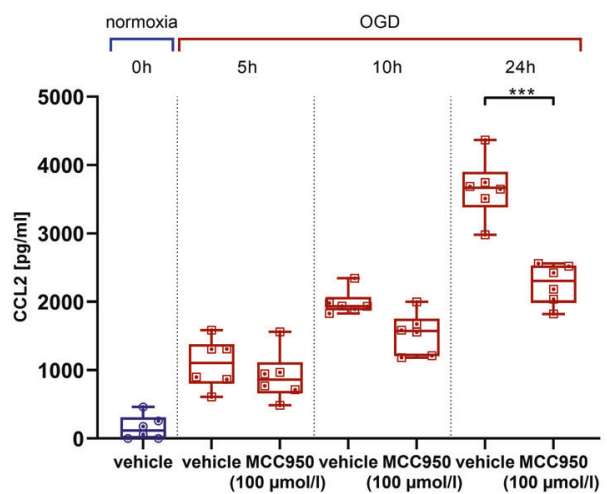

(b)

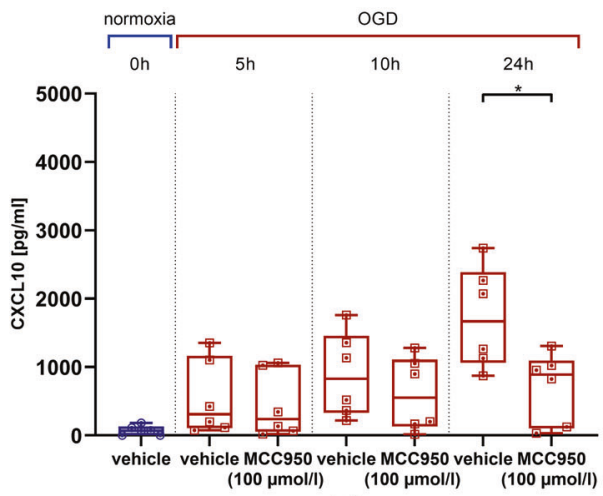

(d)

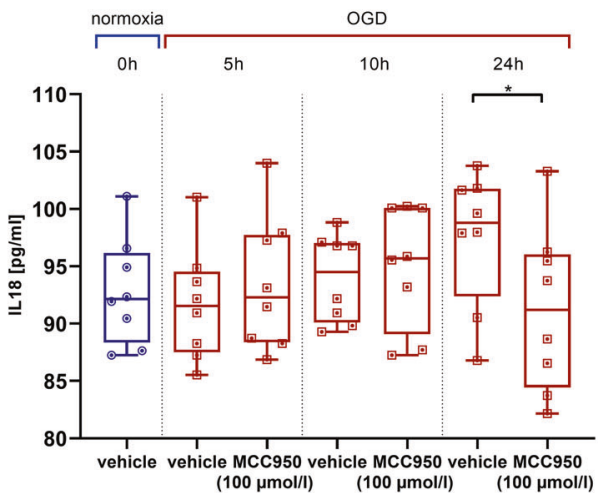

(f)

Fig. 4 bEnd5 express less pro-inflammatory chemokines and cytokines after MCC950 (100 $\mu$ mol/l) treatment. a-d Cytometric bead array to detect endothelial chemokine release depending on OGD $\left(3.0 \% \mathrm{O}_{2}, 5.0 \% \mathrm{CO}_{2}, 95 \%\right.$ humidity, $37.0^{\circ} \mathrm{C}, 1 \mathrm{~g} / \mathrm{l}$ glucose, red) duration and treatment regime. a CXCL1 protein concentration $(n=6$ out of three independent experiments), b CCL2 (MCP-1) protein concentration ( $n=6$ out of three independent experiments), c CCL5 (RANTES) protein concentration ( $n=6$ out of three independent experiments) and d CXCL10 (IP10) protein concentration ( $n=6$ out of three independent experiments) at baseline under normoxic conditions as well as after $5 \mathrm{~h}, 10 \mathrm{~h}$, and $24 \mathrm{~h}$ of OGD with vehicle or MCC950 treatment. e-f ELISA to measure endothelial cytokine release depending on OGD duration and treatment regime. e IL $1 \mathrm{~b}$ protein concentration ( $n=8$ out of four independent experiments), $f$ IL 18 protein concentration ( $n=8$ out of four independent experiments). Data were analyzed by unpaired $t$ test. ${ }^{*} p<0.05 ;{ }^{* *} p<0.01 ;{ }^{* *} p<0.001$.

under normoxic and ischemic conditions [19-21]. To visualize cell death PI was administered. At first, a significant increase of dead bEnd5 after $24 \mathrm{~h}$ of OGD in comparison to bEnd5 under normoxic conditions was observable. Subsequently, in order to check the effect of MCC950 on these bEnd5 under OGD, a dilution series of the NLRP3 inhibitor was accomplished. It could be clearly shown that a MCC950 concentration of $100 \mu \mathrm{mol} / \mathrm{l}$ leads to the highest bEnd5 survival rate within the OGD setting while higher concentrations seemed to have a toxic and lower concentration an insufficient effect (Fig. 1, Figure S1). To verify the de facto NLRP3 expression on bEnd5, Western Blot analysis of bEnd5 lysates was performed, firstly after normoxic conditions and secondly after $24 \mathrm{~h}$ of OGD either with or without MCC950 treatment. An NLRP3 expression could be detected in general, with an NLRP3 protein upregulation after OGD. Under OGD conditions, significantly fewer NLRP3 was measurable after MCC950 application in comparison to vehicle treatment. NLRP3 immunofluorescence stainings of bEnd5 cell cultures after $24 \mathrm{~h}$ 


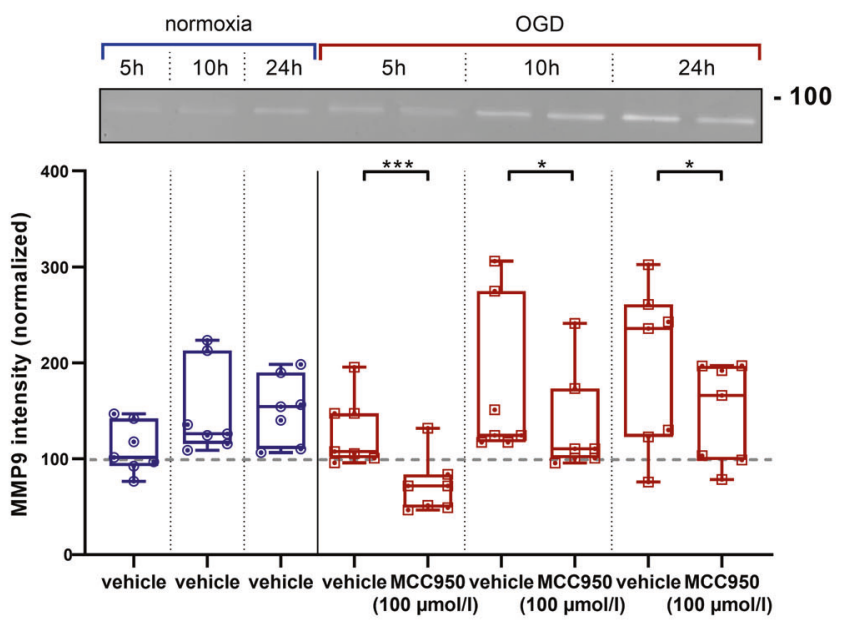

(a)

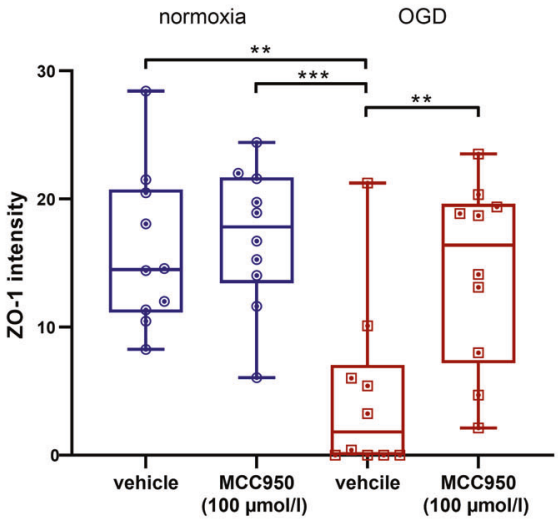

(b)
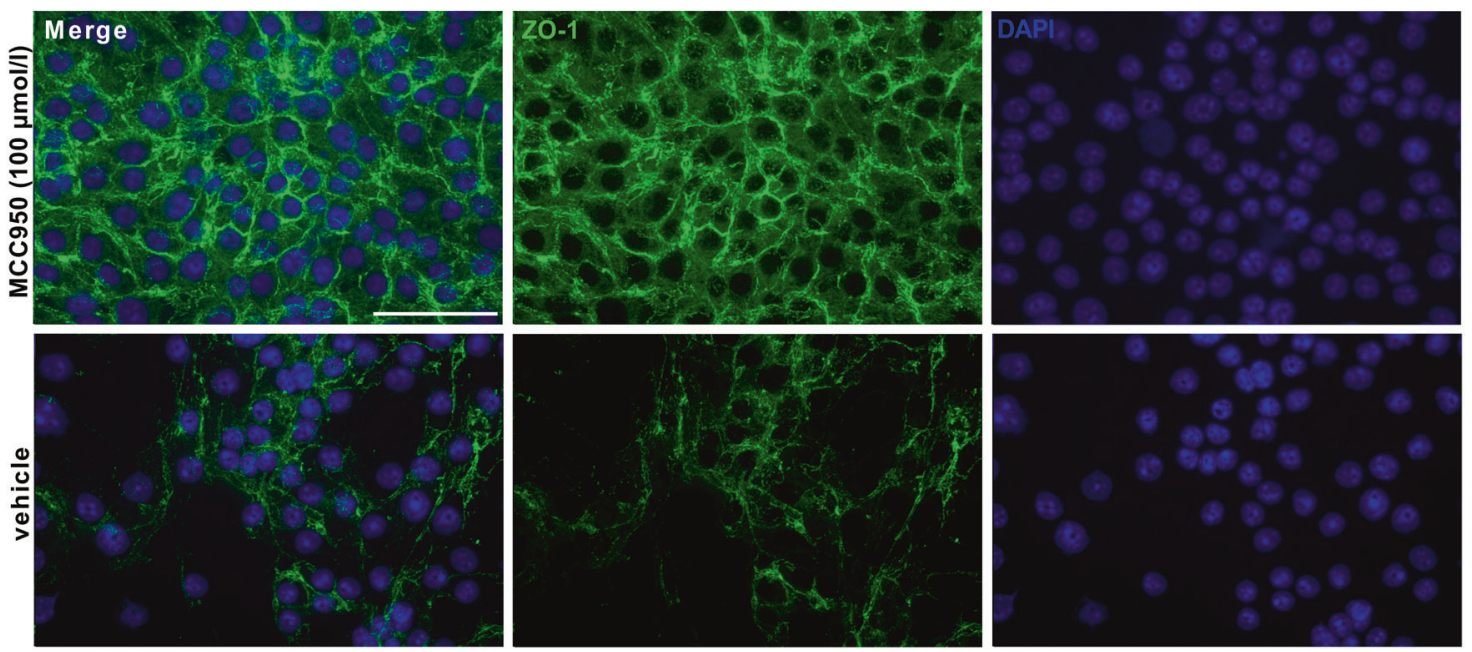

(c)

Fig. 5 MMP9 reduction and ZO-1 enhancement after MCC950 (100 $\mathrm{mmol} / \mathrm{I})$ treatment. a Top: representative zymography with Coomassie staining depicting the amounts of secreted MMP9 $(92 \mathrm{kDa})$ in bEnd5 supernatants after $5 \mathrm{~h}, 10 \mathrm{~h}$, or $24 \mathrm{~h}$ of normoxia (blue) or OGD (3.0\% $\mathrm{O}_{2}$, $5.0 \% \mathrm{CO}_{2}, 95 \%$ humidity, $37.0^{\circ} \mathrm{C}, 1 \mathrm{~g} / \mathrm{l}$ glucose, red) either with vehicle or MCC950 $(100 \mu \mathrm{mol} / \mathrm{l})$ treatment. Bottom: the intensity of MMP9 within the bEnd5 supernatants were normalized to the intensity of the probes at $0 \mathrm{~h}$ under normoxic conditions (dashed line, $n=7$ out of three independent experiments). Data were analyzed by unpaired $t$ test. ${ }^{*} p<0.05 .{ }^{* *} p<0.001$. $\mathbf{b}$ Intensities of ZO-1 immunohistochemical stainings of bEnd5 under normoxia or OGD with either vehicle or MCC950 (100 $\mu \mathrm{mol} / \mathrm{l})$ treatment. Data were analyzed by one-way ANOVA with Tukey post hoc test. ${ }^{* *} p<0.01 ;{ }^{* * *} p<0.001$. c Representative ZO-1 (green) and DAPI (blue) immunofluorescence stainings of bEnd5 after $24 \mathrm{~h}$ of OGD either with vehicle or with MCC950 $(100 \mu \mathrm{mol} / \mathrm{l})$ treatment. $\times 20$ objective; scale bar $=50 \mu \mathrm{m}$.

OGD revealed a reduced NLRP3 expression after MCC950 treatment, too (Fig. 2).

\section{NLRP3 mediates pyroptosis of EC}

To further specify the type of cell death accompanying the upregulated NLRP3 expression in EC under OGD conditions, we explored evidence for pyroptosis. As a first finding, we demonstrated immunohistochemically elevated levels of the activated form (p20) and reduced levels of the pro-form (p45) of Caspase 1 in vehicletreated cells after OGD (Fig. 3a, b). Moreover, MCC950 $(100 \mu \mathrm{mol} / \mathrm{l})$ treatment led to increased immunohistochemical intensities in the staining of uncleaved GSDMD and reduced intensities of the cytotoxic cleaved N-terminal GSDMD (Fig. 3c, d). These protective effects of MCC950 were confirmed in the respective Western Blot analyses (Fig. 3e, f) [22-24]. With that, we could clarify that the increased levels of uncleaved GSDMD are a reliable indirect indicator for reduced pyroptosis after MCC950 therapy.
NLRP3 inhibition attenuates post-ischemic chemokine, cytokine, and MMP9 release

We aimed to evaluate the impact of the NLRP3 inhibition on the release of pro-inflammatory chemokines by EC under ischemic pressure. Therefore, a cytometric bead array was performed to measure the protein concentrations of the endothelial proinflammatory chemokines CXCL1, CCL2 (MCP-1), CCL5 (RANTES), and CXCL10 (IP10) depending on the duration of OGD and treatment regime. The expression of the respective proteins was matched between an initial value at $0 \mathrm{~h}$ under normoxic conditions and MCC950/vehicle-treated bEnd5 after $5 \mathrm{~h}, 10 \mathrm{~h}$, and $24 \mathrm{~h}$ of OGD. Upregulation of pro-inflammatory chemokines could be detected in vehicle-treated bEnd 5 that reached statistical significance after $24 \mathrm{~h}$ of OGD (Fig. $4 \mathrm{a}-\mathrm{d}$ ). The same was evaluated with regard to pro-inflammatory cytokines related to the pyroptosis pathway: again a significant reduction of IL $1 \mathrm{~b}$ protein concentration already after $5 \mathrm{~h}$ of OGD and of IL18 after $24 \mathrm{~h}$ of 


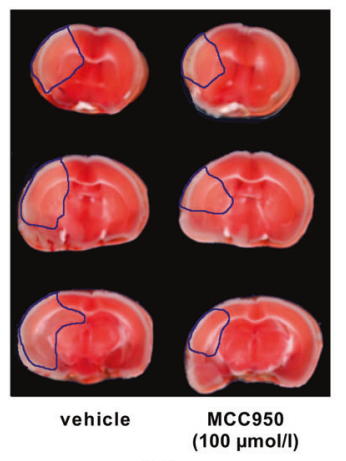

(a)

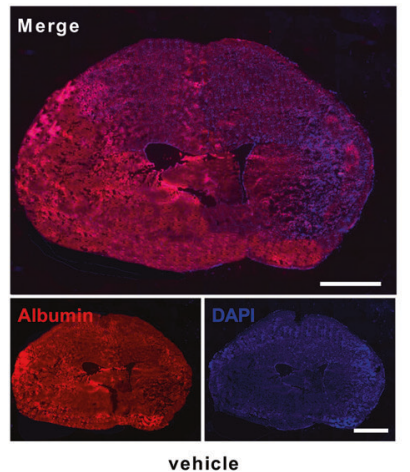

(e)

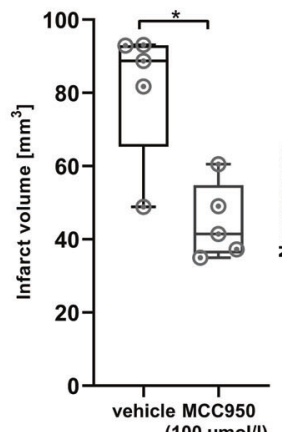

(b)

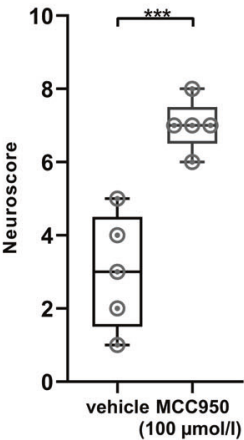

(c)

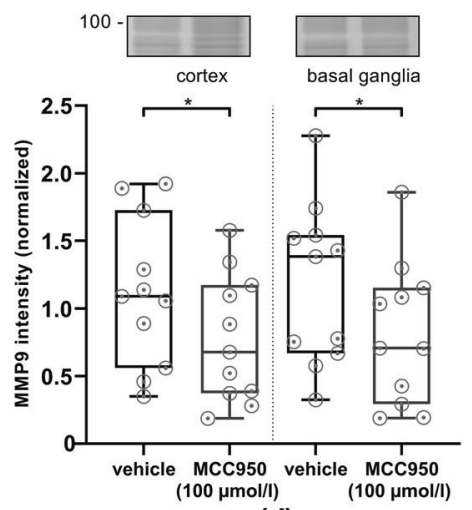

(d)

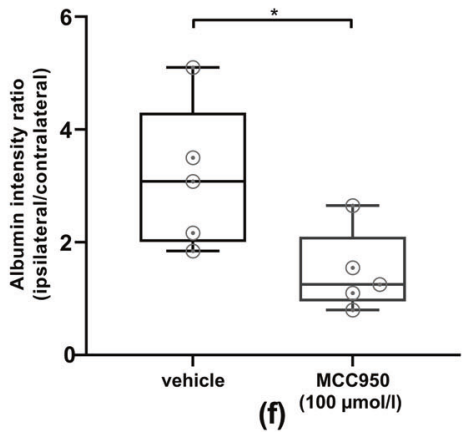

Fig. 6 Treatment with the inflammasome-inhibitor MCC950 $(100 \mu \mathrm{mol} / \mathrm{l})$ reduces stroke severity, improves neurological outcome, reduces MMP9 levels, and lessens BBB disruption. a Representative 2,3,5-triphenyltetrazolium chloride staining of three consecutive coronal brain sections of vehicle- and MCC950 $(100 \mu \mathrm{mol} / \mathrm{l})$ treated mice euthanized $24 \mathrm{~h}$ after tMCAO. The infarcts (circled by blue line) are smaller in the MCC950 (100 $\mu \mathrm{mol} / \mathrm{l})$-treated mice, which could be confirmed by $\mathbf{b}$ infarct volumetry $(n=5)$. c Neurologic scores were performed $1 \mathrm{~d}$ after tMCAO $(n=5)$. d Top: representative zymography with Coomassie staining depicting the amounts of secreted MMP9 (92 kDa) in ipsilesional cortical or basal ganglial brain lysates $1 \mathrm{~d}$ after tMCAO with and without NLRP3 inhibition (MCC950 100 $\mu \mathrm{mol} / \mathrm{l})$. Bottom: densitometric quantification of MMP9 within the brain lysates with normalization to the intensity of the total protein of the respective probe as displayed by the Coomassie staining $(n=11)$. e Representative immunohistological staining of albumin (red) and nuclei (DAPI, blue) of coronal brain slices $1 \mathrm{~d}$ after tMCAO in a vehicle (left) and MCC950 $(100 \mu \mathrm{mol} / \mathrm{l})$ treated mouse (right) using $\times 5$ objective. scale bar $=2 \mathrm{~mm}$. $\mathbf{f}$ Ratio of ipsilesional to contralesional albumin intensity of coronary brain slices $1 \mathrm{~d}$ after tMCAO in vehicle and MCC950 (100 $\mu \mathrm{mol} / \mathrm{l})$ treated mice $(n=5)$. Data were analyzed by unpaired $t$ test. ${ }^{*} p<0.05 ;{ }^{* *} p<0.001$.

OGD could be demonstrated after MCC950 $(100 \mu \mathrm{mol} / \mathrm{l})$ treatment compared with vehicle treatment (Fig. $4 \mathrm{e}-\mathrm{f}$ ).

Moreover, zymography was performed with bEnd5 supernatants. Monocultured EC displayed a timedependent increase of MMP9 levels after OGD [18, 25]. Within the MCC950-treated groups a significant decrease in comparison with vehicle-treated cells was observable (Fig. 5a). Furthermore, ZO-1 was stained and showed a significantly higher immunofluorescent intensity after MCC950 treatment, demonstrating that the effects of NLRP3 inhibition are not limited to higher survival of EC but also involve tight junction proteins (Fig. 5b, c).

NLRP3 inhibition mitigates post-ischemic BBB disruption and cell death within the vascular compartment in vivo

To translate these findings in an in vivo model, the tMCAO model was conducted with $C 57 \mathrm{BI} / 6 \mathrm{~N}$ WT mice either with or without MCC 950 treatment. Stroke volumes were diminished by $\sim 40 \%$ and functional outcome improved significantly as revealed by the neuroscore on day 1 , compared with vehicletreated control animals (Fig. $6 \mathrm{a}-\mathrm{c}$ ). A key parameter characterizing neuroinflammatory processes within IS is the breakdown of the BBB measured by intracerebral albumin extravasation $[26,27]$. Comparing the immunohistochemical albumin intensity $24 \mathrm{~h}$ after $\mathrm{TMCAO}$ a significant $50 \%$ reduction of the ipsilateral to contralateral albumin intensity ratio could be detected after
MCC950 treatment (Fig. 6e-f). Moreover, zymography was performed to analyze MMP9 levels after IS [18, 28]. A significant reduction of MMP9 release in the ipsilateral cortices and basal ganglia of MCC950-treated mice compared with vehicle treatment was observable, comparable to the in vitro results (Fig. 6d). At the same time, we were able to depict a significant reduction of cell death within CD31-positive EC in the ischemic brain after MCC950 treatment. This reduction was accompanied by an increase of inactive, uncleaved GSDMD as shown in the cell culture model before (Fig. 7).

\section{DISCUSSION}

As a principal finding, we show that inhibition of the NLRP3 inflammasome with MCC950 reduces EC death-and here in particular pyroptosis-during IS. Within the last years, the NLRP3 inflammasome-mediated pyroptosis has been identified as a potential cause of EC death [10]. So far, a direct contribution of NLRP3-mediated inflammatory processes in EC had mainly been described in the context of systemic vascular endothelial dysfunction [10, 28]. In 2015, the NLRP3 inflammasome-inhibitor MCC950 that specifically inhibits the NLRP3 activation and IL1b, IL18, and GSDMD secretion by preventing the NLRP3-induced ASC oligomerization was firstly described [29]. The studies were performed in macrophages. Later, we were able to highlight the 


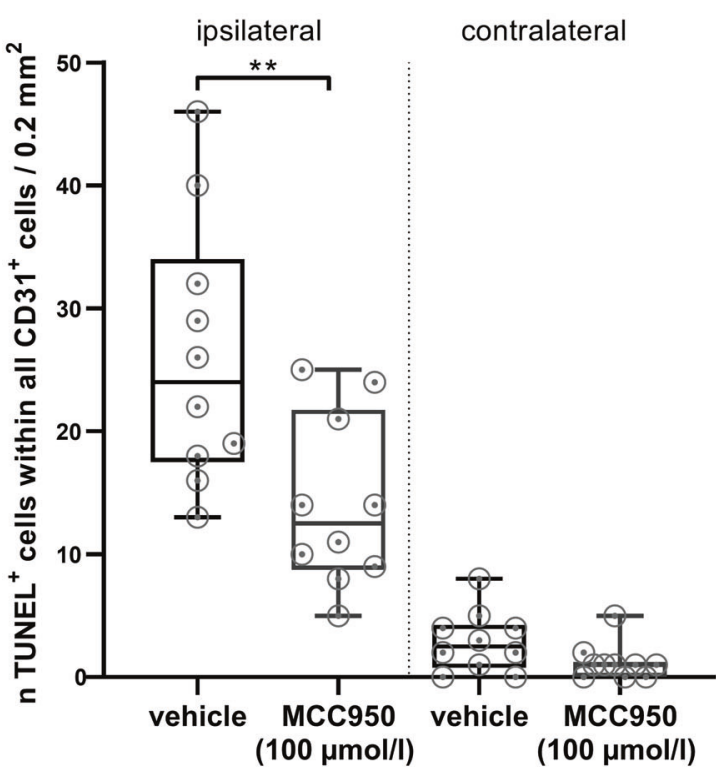

(a)
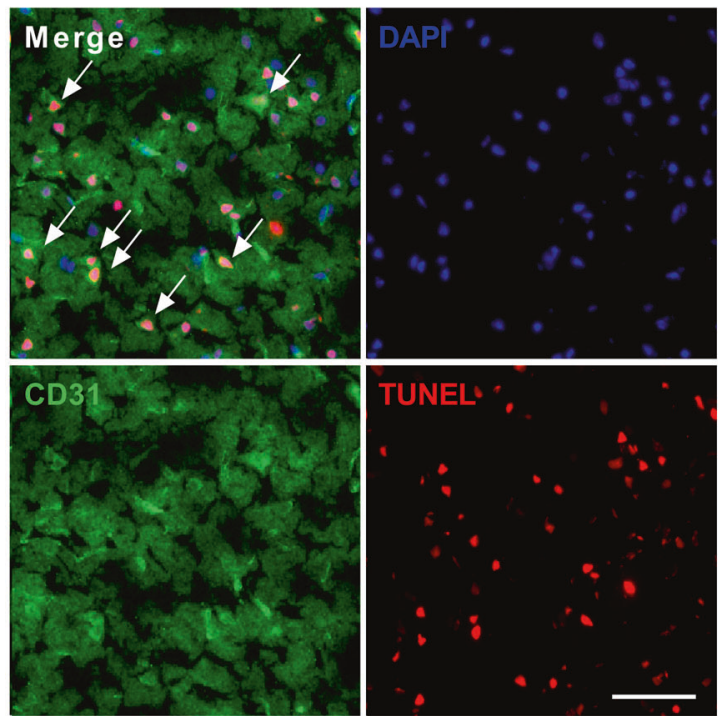

vehicle

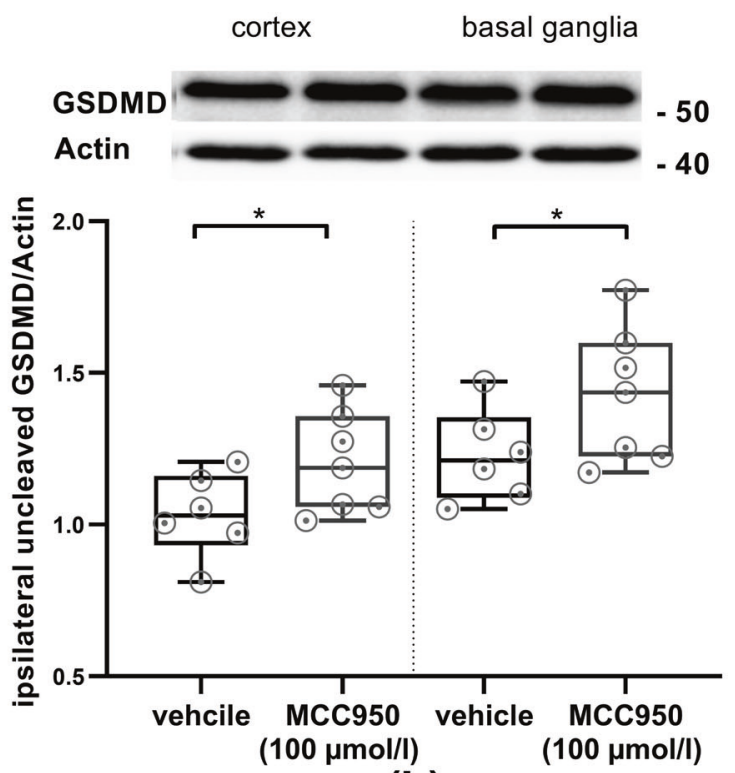

(b)
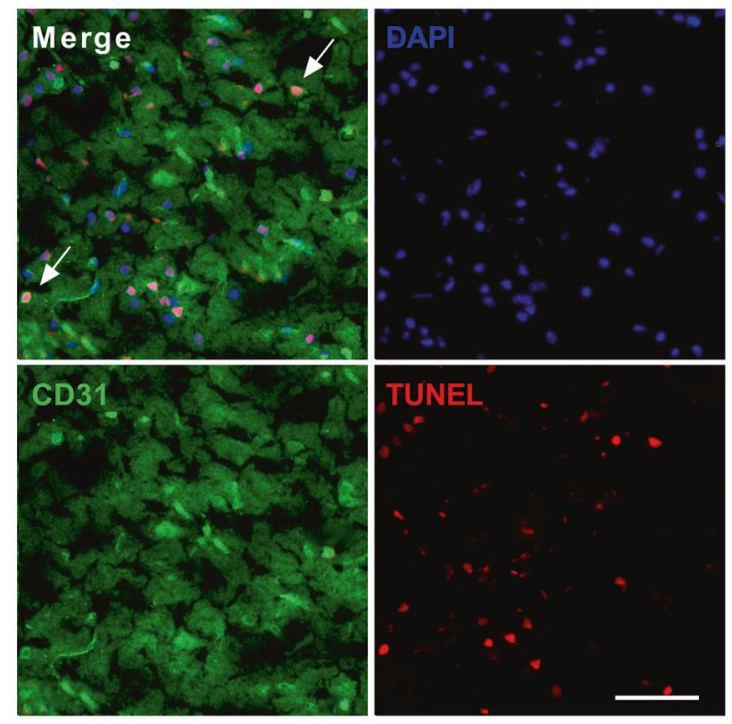

MCC950

$(100 \mu \mathrm{mol} / \mathrm{l})$

(c)

Fig. 7 MCC950 $(100 \mu \mathrm{mol} / \mathrm{l})$ treatment reduces cell death within the vascular compartment after IS. Uncleaved GSDMD levels indicate reduced pyroptosis after inflammasome inhibition. a The number of CD31- and TUNEL-positive cells within all CD31-positive cells (ipsilateral or contralateral) of vehicle or MCC950 $(100 \mu \mathrm{mol} / \mathrm{l})$ treated animals on day 1 after tMCAO $(n=10$, two per animal). b Uncleaved GSDMD $(52 \mathrm{kDa})$ protein content in the cortex or basal ganglia of vehicle or MCC950 $(100 \mu \mathrm{mol} / \mathrm{l})$ treated mice. For densitometric quantification actin was used as a loading control (expected mass $\sim 2 \mathrm{kDa})(n=7)$. c Representative brain sections from vehicle (left) or MCC950 (100 $\mu \mathrm{mol} / \mathrm{l})$ (right) treated mice $24 \mathrm{~h}$ after tMCAO immunolabeled for the marker CD31 (green), TUNEL (red) to depict apoptosis and DAPI (blue) for nuclei. White arrows highlight triple-positive cells. In all, $\times 20$ objective, scale bar $=100 \mu \mathrm{m}$. Data were analyzed by unpaired $t$ test. ${ }^{*} p<0.05 ;{ }^{* *} p<$ 0.01 .

efficacy of MCC950 also in neurons [9]. Recently, the beneficial effect of MCC950 on the BBB integrity after intracerebral hemorrhage has been demonstrated [30]. But the potential impact of NLRP3 inflammasome activation in highly specialized brain EC on IS-induced endothelial dysfunction and subsequent BBB breakdown had remained elusive.

In previous as well as in the present study, we have shown the potential of global NLRP3 inhibition to stabilize the BBB in an in vivo stroke model [9]. We now extend these findings by specifically addressing the role of endothelial NLRP3 under hypoxia/hypoxemia. We took advantage of bEnd5 cells, which are highly sensitive to short exposures to OGD, to study the consequences of NLRP3 activation in EC without confounding hemodynamic variables and cell types $[20,31]$. After determining the optimal concentration of MCC950 treatment within the OGD setting, we could show that bEnd5 express NLRP3 protein, and importantly could be downregulated after MCC950 treatment during OGD. This was associated with higher survival of the EC as well as a stabilization of surrounding tight junctions. Cell death relating to inflammasome activation is attributed to 
pyroptosis [32]. We found upregulated cleaved Caspase 1 as well as respective GSDMD levels - the latter both in vitro and in vivo. In addition, we could show that NLRP3 inhibition reduced the secretion of pro-inflammatory chemokines and cytokines in vitro. This is in good agreement with previous in vivo findings depicting decreased immune cell infiltration into the ischemic hemisphere after tMCAO and MCC950 treatment [9]. Besides chemokines and cytokines, MMPs are a driving force for BBB destructing processes, too. A significant increase in MMP9 expression after rt-PA administration, accompanied by BBB disruption and ultimately hemorrhagic transformation, had been described [33]. In clinical studies, MMP9 has been shown to correlate with an increased risk of mortality and major disability as well as infarct volume growth after IS [34]. In our study, treatment of bEnd5 with MCC950 decreased the amount of MMP9 secretion during OGD. To close the loop, we analyzed MMP9 expression in our tMCAO mice and could present the very same outcome: NLRP3 inhibition reduced the amount of MMP9 in the ischemic hemispheres.

The positive effect of NLRP3 inhibition on the BBB integrity after IS can thus be explained by a dual mechanism: [1] Protection of the BBB itself due to fewer pyroptosis of EC and [2] less proinflammatory signaling cascades leading to fewer local inflammation. Which target actually produces therapeutic effects is a recurrent question in the NLRP3 inflammasome research [35]. With our results, we can clearly outline the detrimental role of endothelial NLRP3 in IS.

Besides its role in the acute inflammation in IS, the NLRP3 inflammasome has been demonstrated to contribute to chronic inflammatory processes resulting in premature endothelial senescence $[36,37]$. Interestingly, the incidence of Alzheimer's disease (AD) increases several-fold after acute IS $[38,39]$. This might be explained at least to some extent by the contribution of inflammatory mediators to secondary brain damage in both $A D$ and stroke [40]. The NLRP3 inflammasome is able to sense the accumulation of danger-associated molecular patterns during aging and mediates pro-inflammatory cascades. The inhibition of abnormal NLRP3-activity during aging has been shown to attenuate age-associated innate immune activation, age-related chronic diseases, and prolong healthspan [37]. It is therefore promising that the acute treatment with NLRP3 inhibitors such as MCC950 does not only lessen the neuroinflammation in IS and improve the post-stroke neurologic outcome but also reduce the incidence of $A D$ after IS.

In conclusion, our findings establish the NLRP3 inflammasome as a major mediator of inflammation and pyroptosis in brain EC that ultimately plays a key role in BBB breakdown in IS. Therefore, NLRP3 represents a potential pharmacological target in acute IS therapy.

\section{DATA AVAILABILITY}

Any additional data will be provided upon reasonable request.

\section{REFERENCES}

1. del Zoppo GJ, Saver JL, Jauch EC, Adams HP. Expansion of the time window for treatment of acute ischemic stroke with intravenous tissue plasminogen activator: a science advisory from the american heart association/american stroke association. Stroke 2009;40:2945-8.

2. Wang X. Mechanisms of hemorrhagic transformation after tissue plasminogen activator reperfusion therapy for ischemic stroke. Stroke 2004;35:2726-30.

3. Kelly MA, Shuaib A, Todd KG. Matrix metalloproteinase activation and blood-brain barrier breakdown following thrombolysis. Exp Neurol. 2006;200:38-49.

4. Kassner A, Merali Z. Assessment of blood-brain barrier disruption in stroke. Stroke 2015;46:3310-5.

5. Yang $Y$, Rosenberg GA. Blood-brain barrier breakdown in acute and chronic cerebrovascular disease. Stroke 2011:42:3323-8. Nov
6. Stoll G, Nieswandt B. Thrombo-inflammation in acute ischaemic stroke implications for treatment. Nat Rev Neurol. 2019;15:473-81.

7. Kollikowski AM, Schuhmann MK, Nieswandt B, Müllges W, Stoll G, Pham M. Local leukocyte invasion during hyperacute human ischemic stroke. Ann Neurol. 2020;87:466-79.

8. Hoffman HM, Broderick $L$. The role of the inflammasome in patients with autoinflammatory diseases. J Allergy Clin Immunol. 2016;138:3-14. Jul

9. Franke M, Bieber M, Kraft P, Weber ANR, Stoll G, Schuhmann MK. The NLRP3 inflammasome drives inflammation in ischemia/reperfusion injury after transient middle cerebral artery occlusion in mice. Brain Behav Immun. 2020;92:221-231.

10. Bai $B$, Yang $Y$, Wang $Q$, Li M, Tian $C$, Liu $Y$, et al. NLRP3 inflammasome in endothelial dysfunction. Cell Death Dis. 2020;11:776.

11. Kilkenny C, Browne W, Cuthill IC, Emerson M, Altman DG. Animal research: reporting in vivo experiments-the ARRIVE guidelines. J Cereb Blood Flow Metab. 2011;31:991-3.

12. Schuhmann MK, Guthmann J, Stoll G, Nieswandt B, Kraft P, Kleinschnitz C. Blocking of platelet glycoprotein receptor lb reduces "thrombo-inflammation" in mice with acute ischemic stroke. J Neuroinflammation. 2017;14:18.

13. Kleinschnitz C, Stoll G, Bendszus $M$, Schuh K, Pauer H-U, Burfeind P, et al. Targeting coagulation factor XII provides protection from pathological thrombosis in cerebral ischemia without interfering with hemostasis. J Exp Med. 2006;203:513-8.

14. Seifert HA, Benedek G, Liang J, Nguyen H, Kent G, Vandenbark AA, et al. Sex differences in regulatory cells in experimental stroke. Cell Immunol. 2017:318:49-54.

15. Schuhmann MK, Kraft P, Stoll G, Lorenz K, Meuth SG, Wiendl H, et al. CD28 superagonist-mediated boost of regulatory $t$ cells increases thromboinflammation and ischemic neurodegeneration during the acute phase of experimental stroke. J Cereb Blood Flow Metab. 2015;35:6-10.

16. Bederson JB, Pitts LH, Tsuji M, Nishimura MC, Davis RL, Bartkowski H. Rat middle cerebral artery occlusion: evaluation of the model and development of a neurologic examination. Stroke 1986;17:472-6.

17. Schuhmann MK, Kraft $P$, Bieber M, Kollikowski AM, Schulze $H$, Nieswandt B, et al. Targeting platelet GPVI plus rt-PA administration but not $\alpha 2 \beta 1$-mediated collagen binding protects against ischemic brain damage in mice. IJMS. 2019;20:2019.

18. Zozulya A, Weidenfeller C, Galla H-J. Pericyte-endothelial cell interaction increases MMP-9 secretion at the blood-brain barrier in vitro. Brain Res. 2008;1189:1-11.

19. Devraj G, Guérit S, Seele J, Spitzer D, Macas J, Khel MI, et al. HIF-1a is involved in blood-brain barrier dysfunction and paracellular migration of bacteria in pneumococcal meningitis. Acta Neuropathol. 2020;140:183-208.

20. Yang $T$, Roder $\mathrm{KE}$, Abbruscato TJ. Evaluation of bEnd5 cell line as an in vitro model for the blood-brain barrier under normal and hypoxic/aglycemic conditions. J Pharm Sci. 2007;96:3196-213.

21. Czupalla CJ, Liebner S, Devraj K. In Vitro Models of the Blood-Brain Barrier. In: Milner R, editor. Cerebral Angiogenesis. pp. 415-37. (Springer New York; 2014). Available from: http://link.springer.com/10.1007/978-1-4939-0320-7_34.

22. Alishahi M, Farzaneh M, Ghaedrahmati F, Nejabatdoust A, Sarkaki A, Khoshnam SE. NLRP3 inflammasome in ischemic stroke: as possible therapeutic target. Int J Stroke. 2019;14:574-91.

23. Murthy P, Durco F, Miller-Ocuin JL, Takedai T, Shankar S, Liang X, et al. The NLRP3 inflammasome and bruton's tyrosine kinase in platelets co-regulate platelet activation, aggregation, and in vitro thrombus formation. Biochem Biophys Res Commun. 2017;483:230-6.

24. Chen S, Mei S, Luo Y, Wu H, Zhang J, Zhu J. Gasdermin family: a promising therapeutic target for stroke. Transl Stroke Res. 2018;9:555-63.

25. Zhong Z, Zhai Y, Liang S, Mori Y, Han R, Sutterwala FS, et al. TRPM2 links oxidative stress to NLRP3 inflammasome activation. Nat Commun. 2013;4:1611.

26. Gotoh O, Asano T, Koide T, Takakura K. Ischemic brain edema following occlusion of the middle cerebral artery in the rat. I: the time courses of the brain water, sodium and potassium contents and blood-brain barrier permeability to $125 \mathrm{i}$ albumin. Stroke. 1985;16:101-9.

27. Franke M, Bieber M, Stoll G, Schuhmann MK. Validity and efficacy of methods to define blood brain barrier integrity in experimental ischemic strokes: a comparison of albumin western blot, igg western blot and albumin immunofluorescence. Methods Protoc. 2021;4:23.

28. Chen Z, Martin M, Li Z, Shyy JY-J. Endothelial dysfunction: the role of sterol regulatory element-binding protein-induced NOD-like receptor family pyrin domain-containing protein 3 inflammasome in atherosclerosis. Curr Opin Lipidol. 2014;25:339-49.

29. Coll RC, Robertson AAB, Chae JJ, Higgins SC, Muñoz-Planillo R, Inserra MC, et al. A small-molecule inhibitor of the NLRP3 inflammasome for the treatment of inflammatory diseases. Nat Med. 2015;21:248-55. 
30. Ren H, Kong Y, Liu Z, Zang D, Yang X, Wood K, et al. Selective NLRP3 (pyrin domain-containing protein 3 ) inflammasome inhibitor reduces brain injury after intracerebral hemorrhage. Stroke 2018;49:184-92.

31. Abbruscato TJ, Davis TP. Combination of hypoxia/aglycemia compromises in vitro blood-brain barrier integrity. J Pharm Exp Ther. 1999;289:668-75.

32. Shi J, Zhao $Y$, Wang $K$, Shi $X$, Wang $Y$, Huang $H$, et al. Cleavage of GSDMD by inflammatory caspases determines pyroptotic cell death. Nature 2015; 526:660-5.

33. Jiang $\mathrm{R}-\mathrm{H}, \mathrm{Zu} \mathrm{Q}-\mathrm{Q}, \mathrm{Xu} \mathrm{X}-\mathrm{Q}$, Wang $\mathrm{B}$, Ding $\mathrm{Y}$, Wang J, et al. A canine model of hemorrhagic transformation using recombinant tissue plasminogen activator administration after acute ischemic stroke. Front Neurol. 2019;10:673.

34. Zhong C, Yang J, Xu T, Xu T, Peng Y, Wang A, et al. Serum matrix metalloproteinase- 9 levels and prognosis of acute ischemic stroke. Neurology 2017;89:805-12.

35. Yang $\mathrm{Y}$, Wang $\mathrm{H}$, Kouadir $\mathrm{M}$, Song $\mathrm{H}$, Shi F. Recent advances in the mechanisms of NLRP3 inflammasome activation and its inhibitors. Cell Death Dis. 2019;10:128.

36. Jia G, Aroor AR, Jia C, Sowers JR. Endothelial cell senescence in aging-related vascular dysfunction. Biochim Biophys Acta. 2019;1865:1802-9.

37. Youm Y-H, Grant RW, McCabe LR, Albarado DC, Nguyen KY, Ravussin A, et al. Canonical Nlrp3 inflammasome links systemic low-grade inflammation to functional decline in aging. Cell Metab. 2013;18:519-32.

38. Desmond DW, Moroney JT, Sano M, Stern Y. Incidence of dementia after ischemic stroke: results of a longitudinal study. Stroke 2002;33:2254-62.

39. ladecola C, Gorelick PB. Converging pathogenic mechanisms in vascular and neurodegenerative dementia. Stroke 2003;34:335-7.

40. Marchesi VT. Alzheimer's dementia begins as a disease of small blood vessels, damaged by oxidative-induced inflammation and dysregulated amyloid metabolism: implications for early detection and therapy. FASEB J. 2011;25:5-13.

\section{ACKNOWLEDGEMENTS}

We thank Susanne Hellmig and Gabi Köllner for excellent technical assistance.

\section{AUTHOR CONTRIBUTIONS}

M.Be., G.S. and M.K.S. performed study concept and design. M.Be., L.Z. and M.Bi. performed experiments. M.Be., P.K., G.S. and M.K.S. analyzed data, discussed results, and provided important intellectual content throughout the study. M.Be., G.S. and M. K.S. wrote the paper with input and approval from all authors. All authors read and approved the final paper.

\section{FUNDING}

This research was funded by Deutsche Forschungsgemeinschaft (DFG) [project 374031971-TRR 240 to M.K.S. (B06) and G.S. (B02); project 413657723 (Clinician Scientist-program UNION CVD) to M.Be.]. This publication was supported by the Open Access Publication Fund of the University of Wuerzburg. Open Access funding enabled and organized by Projekt DEAL.

\section{COMPETING INTERESTS}

The authors declare no competing interests.

\section{ADDITIONAL INFORMATION}

Supplementary information The online version contains supplementary material available at https://doi.org/10.1038/s41419-021-04379-z.

Correspondence and requests for materials should be addressed to Michael K. Schuhmann.

Reprints and permission information is available at http://www.nature.com/ reprints

Publisher's note Springer Nature remains neutral with regard to jurisdictional claims in published maps and institutional affiliations.

(i) Open Access This article is licensed under a Creative Commons Attribution 4.0 International License, which permits use, sharing, adaptation, distribution and reproduction in any medium or format, as long as you give appropriate credit to the original author(s) and the source, provide a link to the Creative Commons license, and indicate if changes were made. The images or other third party material in this article are included in the article's Creative Commons license, unless indicated otherwise in a credit line to the material. If material is not included in the article's Creative Commons license and your intended use is not permitted by statutory regulation or exceeds the permitted use, you will need to obtain permission directly from the copyright holder. To view a copy of this license, visit http://creativecommons. org/licenses/by/4.0/.

(c) The Author(s) 2021 